\title{
SWOT ANALYSIS OF SAVING PRODUCTS IB HIJRAH HAJI PT. BANK MUAMALAT INDONESIA SUPPORTING BRANCH
}

\author{
Vera $^{1}$, Ikhwanuddin Harahap ${ }^{2}$, Windari ${ }^{3}$, Arti Damisa ${ }^{4}$ \\ ${ }^{1}$ IAIN Padangsidimpuan (Perbankan Syariah, FEBI, IAIN Padangsidimpuan) \\ ${ }^{2}$ IAIN Padangsidimpuan (Hukum Syariah, FEBI, IAIN Padangsidimpuan) \\ ${ }^{3}$ IAIN Padangsidimpuan (Ekonomi Syariah, FEBI, IAIN Padangsidimpuan) \\ ${ }^{4}$ IAIN Padangsidimpuan (Perbankan Syariah, FEBI, IAIN Padangsidimpuan) \\ Vera@gmail.com ${ }^{1}$, ikhwanuddinharahap@iain-padangsidimpuan.ac.id ${ }^{2}, \underline{\text { wwindariok@gmail.com }}^{3}$, \\ arti@iain-padangsidimpuan.ac.id $^{4}$
}

\begin{abstract}
ABSTRAK
Salah satu kendala masyarakat Mandailing Natal untuk naik haji adalah besarnya ongkos naik haji. Tabungan IB Hijrah Haji merupakan tabungan yang memudahkan masyarakat untuk mengunjungi Baitullah. Namun masyarakat belum banyak yang mengetahui produk tabungan IB Hijrah Haji ini, dilihat dari jumlah nasabah tabungan IB Hijrah Haji yang mengalami fluktuasi setiap bulannya pada tahun 2018. Rumusan masalah dalam penelitian ini adalah bagaimana analisis SWOT produk Tabungan IB Hijrah Haji PT. Bank Muamalat Indonesia Cabang Pembantu Panyabungan. Tujuan penelitian ini untuk mengetahui perkembangan jumlah nasabah Tabungan IB Hijrah Haji PT. Bank Muamalat Indonesia Cabang Pembantu Panyabungan. Penelitian ini dilakukan pada PT. Bank Muamalat Indonesia Cabang Pembantu Panyabungan dengan metode penelitian kualitatif-deskriptif. Adapun subjek penelitian ini yaitu karyawan PT. Bank Muamalat Indonesia Cabang Pembantu Panyabungan, nasabah tabungan IB Hijrah Haji dan masyarakat Mandailing Natal. Pengumpulan data dengan menggunakan tehnik wawancara dan observasi secara langsung maupun tidak langsung terhadap obyek yang berkaitan dengan yang diteliti serta dokumentasi. Sedangkan Analisis data menggunakan tehnik: editing data, reduksi data dan dekripsi data. Hasil penelitian dengan menggunakan Matriks SWOT menunjukkan bahwa PT. Bank Muamalat Indonesia Cabang Pembantu Panyabungan memiliki kekuatan yang terdiri dari: pelayanan yang cukup baik dan cepat, service mengantar calon jemaah haji dan manasik haji gratis, bebas biaya administrasi, asuransi gratis. Kelemahan tabungan IB Hijrah Haji yaitu: kurangnya SDM pemasaran produk tabungan IB Hijrah Haji, promosi produk masih kurang. Peluang tabungan IB Hijrah Haji ini yaitu: masyarakat yang mayoritas beragama Islam, minat nasabah semakin bertambah untuk menggunakan produk ini, lokasi yang strategis. Sedangkan ancaman tabungan IB Hijrah Haji ini yaitu: persaingan produk yang semakin ketat, lokasi antar bank yang saling berdekatan.
\end{abstract}

Kata Kunci: Analisis SWOT, Produk Tabungan IB Hijrah Haji

\section{ABSTRACT}

One of the obstacles for the Mandailing Natal community to go on a pilgrimage is the high cost of going on a pilgrimage. IB Hijrah Haji Savings is a savings account that makes it easier for people to visit the Baitullah. However, not many people know about this IB Hijrah Haji savings product, seen from the number of IB Hijrah Haji savings customers who experience fluctuations every month in 2018. The problem formulation in this study is how to 
analyze the SWOT product of the IB Hijrah Haji Savings product PT. Bank Muamalat Indonesia Panyabungan Sub-Branch. The purpose of this study was to determine the development of the number of customers of IB Hijrah Haji Savings PT. Bank Muamalat Indonesia Panyabungan Sub-Branch. This research was conducted at PT. Bank Muamalat Indonesia Panyabungan SubBranch with qualitative-descriptive research method. The subjects of this research are employees of PT. Bank Muamalat Indonesia Panyabungan Sub-Branch, IB Hijrah Haji savings customers and the Mandailing Natal community. Collecting data using interview techniques and direct and indirect observations of objects related to the researched and documentation. Meanwhile, data analysis used the following techniques: data editing, data reduction and data decryption. The results of the study using the SWOT Matrix showed that PT. Bank Muamalat Indonesia Panyabungan Sub-Branch has strengths which consist of: fairly good and fast service, service to deliver prospective pilgrims and free Hajj rituals, free administration fees, free insurance. Weaknesses of IB Hijrah Haji savings, namely: lack of human resources marketing IB Hijrah Haji savings products, product promotion is still lacking. The savings opportunities for IB Hijrah Haji are: people who are predominantly Muslim, increasing customer interest in using this product, strategic location. Meanwhile, the threats of IB Hijrah Haji savings are: product competition that is getting tighter, locations between banks that are close to each other.

Keywords: SWOT Analysis, IB Hijrah Hajj Savings Product 
Elna Sriwanna ${ }^{1}$, Ikhwanuddin Harahap ${ }^{2}$, Windari ${ }^{3}$, Ali Hardana ${ }^{4}$, Abdul Nasser Hasibuan ${ }^{5}$ POINT Vol. 1, No. 1, Jul 2020

A. PEndahuluan 


\section{Journal Sharia of Banking}

Bank merupakan perusahaan yang bergerak dalam bidang keuangan, artinya usaha perbankan selalu berkaitan dalam masalah bidang keuangan. Usaha perbankan meliputi tiga kegiatan utama yaitu menghimpun dana, menyalurkan dana, dan memberikan jasa lainnya.

Bank Syariah adalah bank yang beroperasi tanpa mengandalkan bunga. Tujuan utama dari pendirian lembaga keuangan berlandaskan syariah adalah tiada lain sebagai upaya kaum muslim untuk mendasari segenap aspek kehidupan ekonominya berlandaskan alQuran dan As-Sunnah.

PT. Bank Muamalat Indonesia Cabang Pembantu Panyabungan adalah salah satu bank yang beroperasi dengan menggunakan prinsip syariah sehingga mendapat perhatian dan banyak diminati oleh masyarakat Panyabungan. Salah satu produk yang mereka kembangkan adalah produk Tabungan IB Hijrah Haji, dimana produk ini bagian dari produk Bank Muamalat Indonesia.

Tabungan IB Hjrah Haji ialah tabungan dimana nasabah bisa memilih dan mengatur jumlah setoran serta jangka waktu menabung sesuai dengan paket haji atau umrah yang tersedia. Dengan fasilitas asuransi jiwa, Insya Allah pelaksanaanibadah haji tetap terjamin. Dengan keistimewaan tersebut, nasabah Tabungan IB Muamalat Haji dan Umrah bisa merencanakan jadwal waktu keberangkatannya sendiri dengan setoran tetap tiap bulan, keberangkatan nasabah terjamin dengan asuransi jiwa.

Tabel 1 Perkembangan Jumlah Nasabah

Tabungan IB Hijrah Haji PT. Bank Muamalat Indonesia Cabang Pembantu Panyabungan

\begin{tabular}{|c|c|c|}
\hline No & Bulan & $\begin{array}{c}\text { Jumlah Nasabah Tahun } \\
2018\end{array}$ \\
\hline 1 & Januari & 25 \\
\hline 2 & Februari & 15 \\
\hline 3 & Maret & 14 \\
\hline 4 & April & 14 \\
\hline 5 & Mei & 6 \\
\hline 6 & Juni & 12 \\
\hline 7 & Juli & 22 \\
\hline 8 & Agustus & 26 \\
\hline
\end{tabular}

\begin{tabular}{|c|c|c|}
\hline 9 & September & 20 \\
\hline 10 & Oktober & 22 \\
\hline 11 & November & 27 \\
\hline 12 & Desember & 31 \\
\hline
\end{tabular}

Dari data tersebut membuktikan bahwa jumlah nasabah Tabungan IB Hijrah Haji tahun 2018 setiap bulannya mengalami fluktuasi. Dan setiap perusahaan pasti menginginkan keuntungan/laba. Hal ini menjadi permasalahan dikarenakan produk tersebut sangat membantu pelaksanaan ajaran syariah dan juga rukun Islam kelima yang tidak dapat mengalami pertumbuhan secara signifikan. Dari data tersebut menjelaskan bahwa adanya kenaikan dan penurunan jumlah nasabah yang disebabkan oleh faktor internal dan faktor eksternal perusahaan.

Selama melaksanakan praktik magang di PT. Bank Muamalat Indonesia Cabang Pembantu Panyabungan mulai tanggal 30 Oktober sampai dengan 13 November 2018 peneliti melakukan survei ke masyarakat namun yang terjadi beberapa masyarakat sekitar Bank Muamalat Indonesia Cabang Pembantu Panyabungan belum mengetahui produk Tabungan IB Hijrah Haji.

Dari fenomena yang telah dijelaskan menunjukkan bahwa berbagai kekuatan belum mampu dimaksimalkan untuk memanfaatkan peluang yang ada. Adanya tantangan belum dijawab dengan pasti, serta berbagai ancaman yang belum bisa teratasi membuat perkembangan nasabah produk Tabungan IB 
Elna Sriwanna ${ }^{1}$, Hkwwanuddin Harahap ${ }^{2}$, Windari ${ }^{3}$, Ali Hardana ${ }^{4}$, Abdul Nasser Hasibuan ${ }^{5}$

POINT Vol. 1, No. 1, Jul 2020

Hijrah Haji perlu diupayakan secara terus menerus. Maka peneliti tertarik untuk menganalisis apa saja yang menjadi kekuatan, kelemahan, peluang dan ancaman dari bank tersebut yang bisa disebut dengan analisis SWOT.

SWOT merupakan salah satu instrumen analisis yang ampuh apabila digunakan dengan tepat. Telah diketahui pula seacara luas bahwa SWOT merupakan akronim untuk kata-kata Strenght (Kekuatan), Weakness (Kelemahan), Opportunity (Peluang), Threats (Ancaman). Faktor kekuatan dan kelemahan terdapat dalam tubuh suatu organisasi termasuk satuan bisnis tertentu sedangkan peluang dan ancaman merupakan faktor-faktor lingkungan yang dihadapi oleh organisasi atau perusahaan atau satuan bisnis yang bersangkutan.

Analisis SWOT memberikan informasi bagaimana sebenarnya profil keunggulan bersaing. Saat ini peluang Bank Muamalat Indonesia Cabang Pembantu Panyabungan untuk mengembangkan produknya terbuka lebar, namun demikian tantangan yang dihadapinya juga semakin kompleks. Tantangan itu berupa ketatnya persaingan pada bisnis, selain mempertahankan dan meningkatkan produk, perkembangan produk juga berhadapan langsung dengan perbankan konvensional.

Berdasarkan urain di atas, maka peneliti tertarik untuk melakukan penelitian agar memperoleh informasi yang jelas disertai bukti yang ilmiah mengenai penelitian yang 
deskriptif, yaitu penelitian yang berusaha mendeskripsikan suatu gejala, peristiwa kejadian yang terjadi saat sekarang.

Unit analisis dalam penelitian merupakan satuan yang menunjuk pada subjek penelitian. Unit analisis ini dilakukan oleh penelitian agar validitas dan reabilitas peneliti dapat terjaga. Unit analisis suatu penelitian dapat berupa individu, kelompok, organisasi, benda, wilayah dan waktu tertentu sesuai dengan fokus permasalahannya.

Subjek penelitian adalah subjek yang dituju untuk diteliti oleh peneliti. Dalam penelitian ini yang menjadi subjek penelitian adalah karyawan maupun staf yang menangani produk Tabungan IB Hijrah Haji, nasabah tabungan IB Hijrah Haji, dan masyarakat kabupaten Mandailing Natal.

Adapun data yang digunakan dalam penelitian ini menggunakan dua sumber data yaitu dalam penelitian ini untuk mendapatkan data primer dapat diperoleh dari karyawan PT. Bank Muamalat Indonesia Cabang Pembantu Panyabungan berupa hasil wawancara dan observasi. Dalam penelitian ini yang menjadi sumber aslinya adalah PT. Bank Muamalat Indonesia Cabang Pembantu Panyabungan. Data sekunder digunakan dalam penelitian ini untuk mengetahui jumlah nasabah Tabungan IB Hijrah Haji yang langsung diperoleh dari pihak PT. Bank Muamalat Indonesia Cabang Pembantu Panyabungan.

Adapun tehnik pengumpulan data pada penelitian ini adalah :
1. Observasi

Observasi merupakan salah satu tehnik operasional pengumpulan data melalui proses pencatatan secara cermat dan sistematis terhadap objek yang diamati secara langsung. terjadi, bagi siapa, kapan, dan sebagainya.

Observasi yang dilakukan pada penelitian ini adalah observasi langsung. Dalam hal ini penelitian melakukan pengamatan terhadap analisis SWOT terhadap Produk Tabungan IB Hijrah Haji yang dilakukan pada PT. Bank Muamalat Indonesia Cabang Pembantu Panyabungan.

\section{Wawancara}

Dalam penelitian ini peneliti melakukan wawancara dengan salah satu karyawan PT. Bank Muamalat Indonesia Cabang Pembantu Panyabungan yang menangani Produk Tabungan IB Hijrah Haji tersebut dengan nasabah Produk Tabungan IB Hijrah Haji dan dengan masyarakat di sekitar Bank Muamalat Indonesia Cabang Pembantu Panyabungan.

3. Dokumentasi

Dokumentasi adalah bentuk alat pengumpulan data selain observasi dari wawancara adalah dokumentasi. Setelah data terkumpul maka dilaksanakan pengolahan dan analisis data dengan tehnik sebagai berikut :

1. Editing data, yaitu reduksi data menjadi suatu susunan kalimat yang sistematis.

2. Reduksi data, yaitu memeriksa kelengkapan data untuk mencari data 
Elna Sriwanna ${ }^{1}$, Ikhwanuddin Harahap ${ }^{2}$, Windari ${ }^{3}$, Ali Hardana ${ }^{4}$, Abdul Nasser Hasibuan ${ }^{5}$

POINT Vol. 1, No. 1, Jul 2020

yang masih kurang dan mengesampingkan yang tidak relevan.

3. Deskripsi data, yaitu menguraikan data secara sistematis untuk mendeskripsikan pelaksanaan penelitian induksi dan deduktif sesuai dengan sistematika pembahasan.

4. Penarikan kesimpulan yaitu kegiatan analisis ketiga terpenting adalah menarik kesimpulan dan verifikasi. Mula-mula kesimpulan kabur, tapi lama-kelamaan semakin jelas karena data semakin banyak dan mendukung.

Adapun pengecekan data yang digunakan adalah :

1. Perpanjangan Keikutsertaan

2. Ketentuan Pengamatan

3. Mengadakan Memberchek

4. Trianggulasi

\section{HASIL DAN PEMBAHASAN}

Tabungan IB hijrah haji adalah simpanan khusus untuk ongkos naik haji yang membantu meringankan niat dan langkah seseorang serta memberi kepastian untuk mewujudkan impian menunaikan ibadah haji ketanah suci. Perkembangan jumlah nasabah Tabungan IB Hijrah Haji saat ini semakin banyak, sehingga ini merupakan peluang bagi bank untuk terus melakukan promosi.

Tabungan IB Hijrah Haji tidak dikenakan biaya administrasi karena tabungan ini menggunakan akad Al-wadiah yad dhamanah yaitu titipan yang bisa dikelola oleh bank dan

nasabah akan mengambil kembali dana yang dititipkan pada waktu yang telah ditentukan. Nasabah hanya membuka rekening dengan saldo minimal Rp. 100.000, kemudian akan ditabung sampai Rp.25.000.000.

Strategi pemasaran yang digunakan PT. Bank Muamalat Indonesia Cabang Pembantu Panyabungan adalah memberikan service berupa layanan mengantar nasabah ke Kantor Departemen Agama (Depag) bagi yang tidak memiliki kendaraan maupun yang memiliki kendaraan, sebagian nasabah yang tidak mengetahui wilayah Panyabungan akan merasa puas dengan layanan jasa antar ke Kantor Departemen Agama (Depag), nasabah akan bercerita kepada kerabat, tetangga atau lainnya tentang pelayanan yang diberikan PT. Bank Muamalat Indonesia Cabang Pembantu Panyabungan sangat bagus. Hal ini menjadi strategi yang sangat bagus untuk menarik minat masyarakat, jika nasabah puas dengan pelayanan bank, maka masyarakat akan mengajak anggota keluarganya yang lain untuk membuka Tabungan di PT. Bank Muamalat Indonesia Cabang Pembantu Panyabungan.

PT. Bank Muamalat Indonesia Cabang Pembantu Panyabungan melakukan promisi Tabungan IB Hijrah Haji melalui pengajian/perwiritan guru madrasah, Dosen STAI Madina, dan lain lain. Tetapi promosi yang paling khusus pada saat manasik haji, disana calon jemaah haji melakukan kegiatan, pada saat jemaah haji melakukan kegiatan, pihak bank melakukan dokumentasi untuk 
dimasukkan ke media masa sebagai promosi. Perkembangan PT. Bank Muamalat Indonesia Cabang Pembantu Panyabungan mengalami peningkatan dari segi penghimpunan dananya.

\section{Kekuatan (Strenght) Produk Tabungan IB}

Hijrah Haji

Faktor dominan yang mempengaruhi peningkatan sejumlah nasabah Tabungan IB Hijrah Haji PT. Bank Muamalat Indonesia Cabang Pembantu Panyabungan yaitu : Mayoritas penduduk daerah Kabupaten Mandailing Natal menganut agama Islam, PT. Bank Muamalat Indonesia Cabang Pembantu Panyabungan memberikan pelayanan yang baik dan kecepatan proses pembukaan buku tabungan sampai dengan pengambilan porsi.

Kelebihan produk Tabungan IB Hijrah Haji Bank Muamalat Indonesia Kantor Cabang Pembantu Panyabungan yaitu : dimana nasabah yang sudah membuka rekening tabungan haji bisa menabung hanya dengan uang Rp.5000 perhari, kemudian bagi calon nasabah haji yang baru membuka tabungan dengan saldo minimal Rp. 5.000 .000 bisa mendapatkan undian umroh. Nasabah yang menggunakan Tabungan IB Hijrah Haji otomatis diberikan asuransi jiwa Manulife tanpa membayar premi tiap bulan, sehingga jika ada nasabah yang meminggal dunia sebelum berangkat haji akan mendapat santunan berupa uang tunai sesuai dengan besaran saldo yang mereka miliki.

Selain itu, PT. Bank Muamalat Indonesia Cabang Pembantu Panyabungan memberikan fasilitas pelayanan berupa manasik haji di
Padangsidimpuan selama satu hari. Calon jemaah haji tidak dipungut biaya mulai dari transportasi pulang pergi serta penginapan.

Kelemahan (Weakness) Produk Tabungan IB Hijrah Haji

Berbagai kelemahan muncul pada produk tabungan IB Hijrah Haji dari awal peluncuran produk sampai dengan sekarang. Tidak hanya bersumber dari bagian internal Bank Muamalat Indonesia sendiri namun juga dari bagian eksternal. Yang menjadi kelemahan produk Tabungan IB Hijrah Haji adalah kurangnya SDM pemasaran pada produk tabungan IB Hijrah Haji dan promosi produk yang masih kurang.

Membahas kelemahan atau kekurangan produk Tabungan IB Hijrah Haji ini dibanding dengan produk Tabungan Haji pesaing mungkin mungkin tidak bisa disimpulkan karena harus ada data pembanding dari bank lain, namun untuk saat ini dapat dikatakan kekurangan dari Tabungan IB Hijrah Haji ini belum ada, karena terlihat dari pertumbuhan nasabah Haji Cabang Pembantu Panyabungan.

Dalam memasarkan produk Tabungan IB Hijrah Haji, Bank Muamalat Indonesia Cabang Pembantu Panyabungan memiliki beberapa kendala, antara lain: wilayah Kabupaten Mandailing Natal termasuk wilayah yang besar dan cukup luas sehingga hampir seluruh lapisan wilayah tidak bisa dikunjungi, misalnuya: Natal, Sinunukan dan daerah lainnya. Bank Muamalat Indonesia Cabang Pembantu Panyabungan berharap dari nasabah yang sudah membuka 
Elna Sriwanna ${ }^{1}$, Hkwwanuddin Harahap ${ }^{2}$, Windari ${ }^{3}$, Ali Hardana ${ }^{4}$, Abdul Nasser Hasibuan ${ }^{5}$

POINT Vol. 1, No. 1, Jul 2020

tabungan haji melakukan promosi dengan menggunakan MLM (Multi Level Marketing), karena jika pihak bank langsung ke daerah yang dituju akan membutuhkan waktu yang cukup lama. Faktor penurunan nasabah Tabungan IB Hijrah Haji disebabkan oleh faktor ekonomi.

Peluang (Opportunity) Produk Tabungan IB

Hijrah Haji

Peluang dari PT. Bank Muamalat Indonesia Cabang Pembantu Panyabungan yaitu: masyarakat yang ada di Panyabungan semakin bertambah dalam hal minat untuk naik haji, dan hal ini akan menjadi kesempatan bagi PT. Bank Muamalat Indonesia Cabang Pembantu Panyabungan. Dan memiliki lokasi yang strategis yang terletak ditengah kota Panyabungan menjadi peluang bagi PT. Bank Muamalat Indonesia Cabang Pembantu Panyabungan untuk meningkatkan nasabah.

Berdasarkan faktor peningkatan dan penurunan jumlah nasabah Tabungan IB Hijrah Haji maka usaha-usaha yang dilakukan Bank Muamalat Indonesia Kantor Cabang Pembantu Panyabungan adalah tetap melakukan promosi berupa pembagian brosur, sosialisasi ke pengajian-pengajian, melakukan sistem marketing MLM (Multi Level Marketing) kepada nasabah yang sudah mendaftar di Bank Muamalat Indonesia Cabang Pembantu Panyabungan. Tetap melakukan komunikasi dengan pegawai Departemen Agama (Kemenag) karena dengan bantuan mereka produk ini banyak diminati oleh masyarakat.
Ancaman (Treat) Produk Tabungan IB Hijrah Haji

Persaingan produk yang semakin ketat yang menyebabkan nasabah semakin kritis dan pandai membanding-bandingkan produk perbankan yang satu dengan yang lainnya, dan banyaknya pesaing PT. Bank Muamalat Indonesia Cabang Pembantu Panyabungan seperti: Bank Syariah Mandiri (BSM), Bank Sumut Syariah (BSS), dan BRI Office Chanelling Syariah. Kemudian lokasi antar bank yang berdekatan menjadikan ancaman bagi PT. Bank Muamalat Indonesia Cabang Pembantu Panyabungan.

Tabel IV.1

Analisis SWOT Produk Tabungan IB Hijrah Haji PT. Bank Muamalat Indonesia Cabang Pembantu Panyabungan

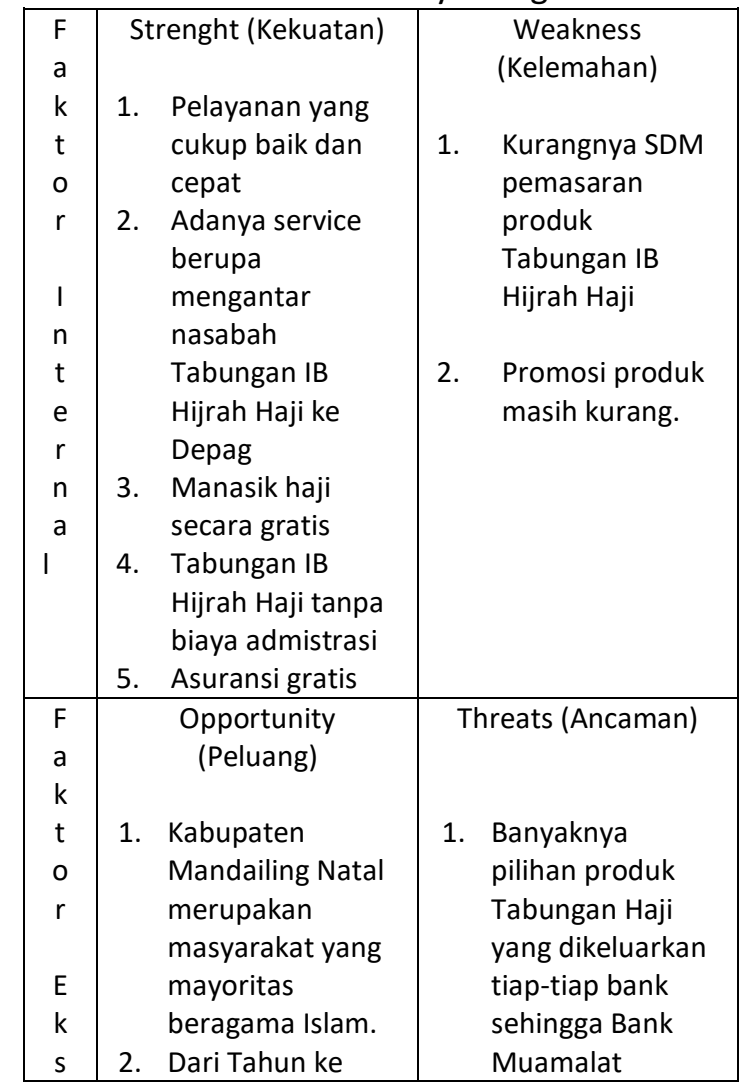




\begin{tabular}{|c|c|c|c|}
\hline $\begin{array}{c}\mathrm{t} \\
\mathrm{e} \\
\mathrm{r} \\
\mathrm{n} \\
\mathrm{a} \\
\mathrm{l}\end{array}$ & 3. & $\begin{array}{l}\text { Tahun kita bisa } \\
\text { lihat bahwa } \\
\text { masyarakat yang } \\
\text { ada di Kabupaten } \\
\text { Mandailing Natal } \\
\text { semakin } \\
\text { bertambah dalam } \\
\text { hal minat untuk } \\
\text { naik haji, dan hal } \\
\text { ini akan menjadi } \\
\text { kesempatan bagi } \\
\text { Bank Muamalat } \\
\text { Indonesia Cabang } \\
\text { Pembantu } \\
\text { Panyabungan } \\
\text { untuk menjalain } \\
\text { kerjasama } \\
\text { dengan } \\
\text { Departemen } \\
\text { Agama (Depag). } \\
\text { Lokasi yang } \\
\text { strategis } \\
\text { menjadikan } \\
\text { peluang bagi } \\
\text { setiap bank untuk } \\
\text { meningkatkan } \\
\text { jumlah nasabah, } \\
\text { seperti PT. Bank } \\
\text { Muamalat } \\
\text { Indonesia Cabang } \\
\text { Pembantu } \\
\text { Panyabungan } \\
\text { yang terletak di } \\
\text { tengah kota } \\
\text { panyabungan } \\
\text { yang berdekatan } \\
\text { dengan pusat } \\
\text { perbelanjaan } \\
\text { yaitu pasar lama } \\
\text { dan pasar baru. }\end{array}$ & $\begin{array}{l}\text { Indonesia Cabang } \\
\text { pembantu } \\
\text { Panyabungan } \\
\text { harus lebih } \\
\text { memaksimalkan } \\
\text { strategi } \\
\text { pemasaran } \\
\text { Tabungan IB } \\
\text { Hijrah Haji. } \\
\text { 2. Persaingan } \\
\text { produk yang } \\
\text { semakin ketat } \\
\text { dan disebabkan } \\
\text { nasabah sudah } \\
\text { cukup kritis dan } \\
\text { pandai } \\
\text { membanding- } \\
\text { bandingkan } \\
\text { produk yang satu } \\
\text { dengan yang lain. } \\
\text { 3. Lokasi antar bank } \\
\text { yang saling } \\
\text { berdekatan }\end{array}$ \\
\hline
\end{tabular}

\section{Formulasi Alternatif Strategi Analisis SWOT}

Berdasarkan EFAS (eksternal strategic factors analysis summary) yaitu ringkasan atau rumusan faktor-faktor strategis eksternal dalam kerangka KESEMPATAN (opportunities) dan ANCAMAN (threats) atau faktor-faktor strategi eksternal perushaan. Dan IFAS (internal strategic factors analysis summary) faktorfaktor strategi internal perusahaan maka kita akan menentukan strategi yang dapat digunakan oleh PT. Bank Muamalat Indonesia Cabang Pembantu Panyabungan dapat melakukan formulasi arah strategi dengan menggunakan matriks SWOT.

Tabel IV.2

Matriks SWOT

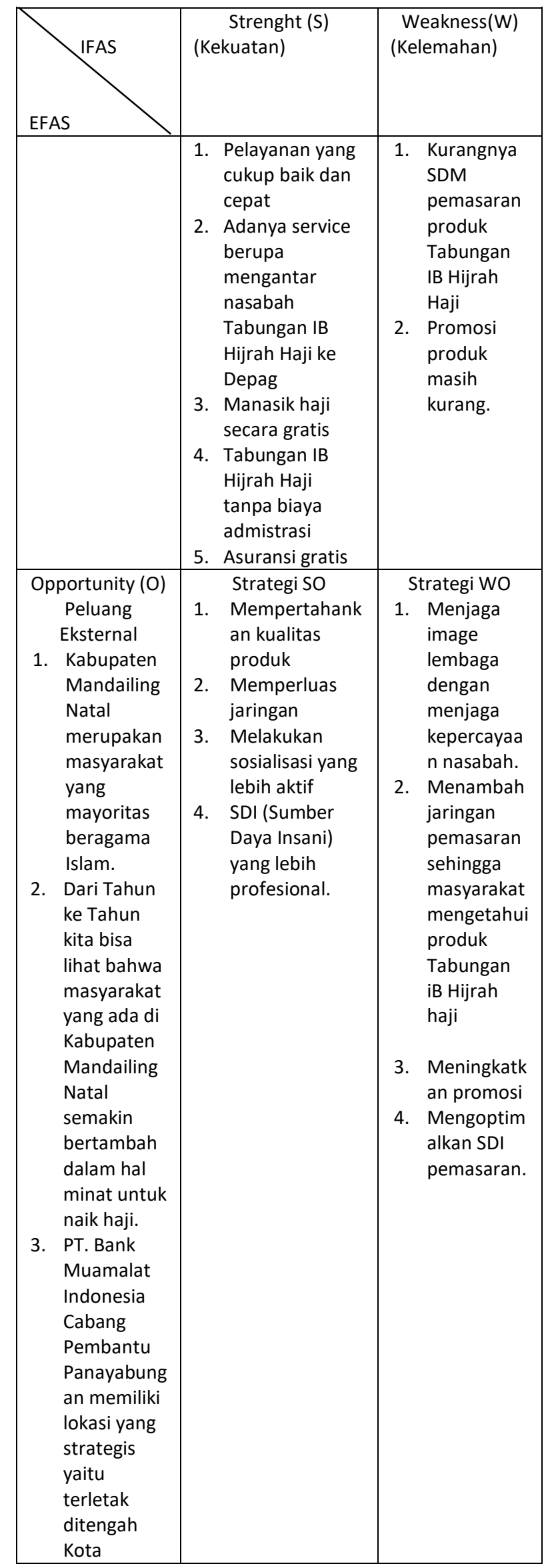




\begin{tabular}{|c|c|c|}
\hline $\begin{array}{l}\text { Panyabunga } \\
\mathrm{n} \text { dan dekat } \\
\text { dengan } \\
\text { pusat } \\
\text { perbelanjaa } \\
\mathrm{n} \text { yaitu } \\
\text { pasar lama } \\
\text { dan pasar } \\
\text { baru. }\end{array}$ & & \\
\hline $\begin{array}{l}\text { Threats (T) } \\
\text { Ancaman } \\
\text { Eksternal } \\
\text { 1. Banyaknya } \\
\text { pilihan } \\
\text { produk } \\
\text { Tabungan } \\
\text { Haji yang } \\
\text { dikeluarkan } \\
\text { tiap-tiap } \\
\text { bank } \\
\text { sehingga } \\
\text { Bank } \\
\text { Muamalat } \\
\text { Indonesia } \\
\text { Cabang } \\
\text { pembantu } \\
\text { Panyabung } \\
\text { an harus } \\
\text { lebih } \\
\text { memaksim } \\
\text { alkan } \\
\text { strategi } \\
\text { pemasaran } \\
\text { Tabungan } \\
\text { IB Hijrah } \\
\text { Haji. } \\
\text { 2. Persaingan } \\
\text { produk } \\
\text { yang } \\
\text { semakin } \\
\text { ketat dan } \\
\text { disebabkan } \\
\text { nasabah } \\
\text { sudah } \\
\text { cukup kritis } \\
\text { dan pandai } \\
\text { membandin } \\
\text { g- } \\
\text { bandingkan } \\
\text { produk } \\
\text { yang satu } \\
\text { dengan } \\
\text { yang lain. } \\
\text { Lokasi antar } \\
\text { bank yang } \\
\text { saling } \\
\text { berdekatan }\end{array}$ & $\begin{array}{l}\text { Strategi ST } \\
\text { 1. Mempertahank } \\
\text { an ciri khas } \\
\text { produk dan } \\
\text { meningkatkan } \\
\text { pelayanan agar } \\
\text { nasabah tetap } \\
\text { merasa puas } \\
\text { 2. Memperluas } \\
\text { daerah } \\
\text { pemasaran } \\
\text { 3. Promosi dan } \\
\text { sosialisai secara } \\
\text { terus menerus }\end{array}$ & $\begin{array}{l}\text { Strategi WT } \\
\text { 1. Selalu } \\
\text { memantau } \\
\text { kepuasan } \\
\text { nasabah } \\
\text { 2. } \text { Mengevalu } \\
\text { asi setiap } \\
\text { kelemahn } \\
\text { 3. } \text { Mencari } \\
\text { kiat-kiat } \\
\text { baru dalam } \\
\text { mensosialis } \\
\text { asikan } \\
\text { produk } \\
\text { Tabungan } \\
\text { IB Hijrah } \\
\text { Haji. } \\
\text { 4. } \text { Menetapka } \\
\mathrm{n} \text { strategi } \\
\text { bisnis baru } \\
\text { yang lebih } \\
\text { efektif dan } \\
\text { efisien } \\
\text { 5. Mempertah } \\
\text { ankan dan } \\
\text { menjaga } \\
\text { nama baik } \\
\text { perusahaan } \\
\text {. }\end{array}$ \\
\hline
\end{tabular}

\section{PENUTUP}

1. Kesimpulan
POINT Vol. 1, No. 1, Jul 2020

Berdasarkan hasil penelitian yang telah dilakukan di PT. Bank Muamalat Indonesia Cabang Pembantu Panyabungan yaitu: Tabungan IB Hijrah Haji adalah simpanan khusus untuk ongkos naik haji. Analisis SWOT adalah sebuah instrumen perencanaan yang memberikan cara sederhana untuk memperkirakan cara terbaik dalam menentukan sebuah strategi. Analisis ini bersifat dekskriptif dan subjektif.

Analisis SWOT merupakan sebuah analisis yang memberikan ouput berupa arahan dalam sebuah permasalahan. Meskipun arahan tersebut bisa diartikan sebagai salah satu bentuk solusi, namun pada dasarnya arahan/rekomendasi yang dihasilkan bertujuan untuk mempertahankan kekuatan dan menambah keuntungan dari peluang yang ada, sekaligus mengurangi kekurangan dan menghindari ancaman terhadap kualitas internal maupun eksternal dari produk Tabungan iB Hijrah Haji.

Analisis SWOT produk Tabungan IB Hijrah Haji menghasilkan strategi S-O (agresif) yakni meningkatkan pelayanan terhadap nasabah, dukungan ulama dan mensosialisasikan keuangan syariah khususnya produk Tabungan IB Hijrah Haji, mempertahankan kualitas produk, melakukan sosialisai lebih aktif, memperluas jaringan, SDI (Sumber Daya Insani) yang kebih profesional. Strategi WO menjaga image lembaga dengan menjaga kepercayaan nasabah, menambah jaringan pemasaran sehingga masyarakat 
mengetahui produk Tabungan IB Hijrah Haji meningkatkan promosi, mengoptimalkan SDI pemasaran. Strategi ST yakni mempertahankan ciri khas produk dengan meningkatkan pelayanan agar nasabah tetap merasa puas, memperluas daerah pemasaran, promosi dan sosialisasi secara terus menerus.

Strstegi WT yakni selalu memantau kepuasan nasabah, mengevaluasi setiap kelemahan, mencari inovasi baru dalam mensosialisasikan produk Tabungan IB Hijrah Haji, menetapkan strategi bisnis yang baru, lebih efektif dan efisien, mempertahankan dan menjaga nama baik perusahaan.

\section{Saran}

Semoga adanya pengetahuan masyarakat terhadap minat produk perbankan syariah

\section{DAFTAR PUSTAKA}

Ascarya, Akad \& Produk Bank Syariah, Jakarta : PT. Raja Grafindo Persada, 2002.

Asmadi Alsa, Pendekatan Kuantitatif Dan Kualitatif, Yogyakarta : Pustaka Pelajar, 2003.

Bank Muamalat Indonesia, Annual Report, Jakarta: Bank Muamalat Indonesia.

Burhan Bungin, Analisis Data Penelitian Kualitatif, Jakarta : PT. Raja grafindo Persada, 2008.

Mulyana Dedy, Metode Penelitian Kualitatif, Bandung : PT. Remaja Rosdakarya, 2003.

Fazar Nur'aini Dwi Fatimah, Tehnik Analisis SWOT, Yogyakarta : Quadrant, 2016.
Fred R. David, Manajemen Strategis Edisi Ke 12, Jakarta : Salemba Empat, 2009.

Fred R. David, Manajemen Stratejik: Suatu Pendekatan Keunggulan Bersaing Edisi Ke 15, Jakarta : Salemba Empat, 2016.

Rangkuti Freddi, Tehnik Membedah Kasus Bisnis Analisis SWOT, Jakarta : PT. Gramedia Pustaka, 2015.

Rangkuti Freddi, SWOT Balanced Scorecard, Jakarta : PT. Gramedia Pustaka, 2011.

Firdaus Rachmat Dan Ariyanti Maya, Manajemen Perkreditan Bank Umum Bandung : alfabeta, 2011.

Suhedi Hendi, Fiqh Muamalah, Jakarta : Rajawali Pers, 2011.

Ikatan Bankir Indonesia, Strategi Sukses Bisnis Bank, Jakarta : PT. Gramedia Pustaka, 2014.

Fahmi Irham, Manajemen Teori, Kasus, dan Solusi, Bandung : Alfabeta Cv, 2012.

J. Salusu, Pengambilan Keputusan Stratejik Untuk Organisasi Publik dan Organisasi Non Publik, Jakarta : PT. Grasindo, 1996.

Subagyo Joko, Metode Penelitian Dalam Teori Dan Praktek, Jakarta : PT. Rineka Cipta, 2004.

Kasmir, Manajemen Perbankan, Jakarta : PT. Raja Grafindo, 2014.

Kasmir, Manajemen Perbankan Edisi Revisi, Jakarta : Rajawali Pers, 2012.

Lexy J. Moleong, Metodologi Penelitian Kualitatif, Bandung : PT. Remaja Rosdakarya, 2000.

Hasan M. Ali , Berbagai Macam Transaksi dalam Islam, Jakarta : PT. Raja Grafindo Persada, 2004. 
Shihab M. Quraish, Tafsir Al-Mishbah Pesan, Kesan dan Keserasian Al-Qur'an Jakarta : Lentera Hati, 2002.

Taufik M. Amir, Manajemen Stratejik, Jakarta : Rajawali Pers, 2012.

Malayu, Dasar-Dasar Perbankan, Jakarta : PT. Bumi Aksara, 2009.

Michael Quinn Patton, Metode Evaluasi Kualitatif, Yogyakarta : Pustaka Pelajar, 2006.

Kotler Philip dan Kevin Lane Keller, Manajemen Pemasaran Edisi Ke 12, Jakarta: PT. Indeks, 2007.

Daft L. Richard., Manajemen Edisi Ke 6, Jakarta : Salemba Empat, 2007.

Senja Nilasari, Manajemen Strategi Itu Gampang, Jakarta : Dunia Cerdas, 2014.

Siagian P. Sondang, Manajemen Stratejik, Jakarta :Bumi Aksara, 1995.

Sugiyono, Metode Penelitian Bisnis, Bandung : Alfabeta, 2014.

Sugiyono, Metode Penelitian Kuantitatif, Kualitatif, dan R\&D, Bandung : Alfabeta, 2013.

Arikunto Suharsimi, Manajemen Penelitian, Jakarta : Rineka Cipta, 1995.

Arikunto Suharsimi, Prosedur Penelitian, Jakarta : Rineka Cipta, 2006.
POINT Vol. 1, No. 1, Jul 2020

Sukardi, Metodologi Penelitian Pendidikan Kompentensi dan Praktiknya, Jakarta: PT. Bumi Aksara, 2003.

Prawirosentono Suryadi dan Dewi Primasari, Manajemen Stratejik \& Pengambilan Keputusan Korporasi, Jakarta : Bumi Aksara, 2014.

Hidayati Ulfa, "Penerapan Analisis Swot Sebagai Strategi Pengembangan Usaha Dalam Perspektif Ekonomi Islam" http.www.repository.radenintan.ac.id, diakses 24 maret 2018 pukul 13.00 wib.

Undang-Undang Republik Indonesia No.21 Tahun 2008, Tentang Perbankan Syariah

Wawancara dengan Bapak Amir Syam Daulay, Nasabah Tabungan IB Hijrah Haji PT. Bank Muamalat Indonesia Kantor Cabang Pembantu Panyabungan, Hari Kamis Tanggal 13 Juni 2019 Pukul 15.00.

Wawancara dengan Bapak Rafahuddin Pulungan, Nasabah Tabungan IB Hijrah Haji PT. Bank Muamalat Indonesia Kantor Cabang Pembantu Panyabungan, Hari Kamis Tanggal 13 Juni 2019 Pukul 14.00.

Wawancara dengan Ibu Fatimah, Nasabah Tabungan IB Hijrah Haji PT. Bank Muamalat Indonesia Kantor Cabang Pembantu Panyabungan, Hari Kamis Tanggal 13 Juni 2019 Pukul 10.00.

Wawancara dengan Ibu Nur Asiah Batubara, Hari Rabu 12 Juni 2019 Pukul 16.00.

www.bankmuamalat.com, diakses tanggal 29 desember 2018, pukul : 16.00 . 